\title{
A multi-compartment model for interneurons in the dorsal lateral geniculate nucleus
}

\author{
Geir Halnes ${ }^{*}$, Sigita Augustinaite ${ }^{2}$, Paul Heggelund ${ }^{2}$, Gaute T Einevoll', Michele Migliore ${ }^{3}$ \\ From Twentieth Annual Computational Neuroscience Meeting: CNS*2011 \\ Stockholm, Sweden. 23-28 July 2011
}

GABAergic interneurons (INs) in the dorsal lateral geniculate nucleus (dLGN) shape the information flow from retina to cortex, presumably by controlling the number of visually evoked spikes in thalamocortical (TC) cells, and refining their receptive field. The dLGN INs exhibit a rich variety of firing patterns. Depolarizing current injections to the soma may induce tonic firing, periodic bursting or an initial burst followed by tonic spiking, sometimes with prominent spike time adaptation. When released from hyperpolarization, some dLGN INs elicit rebound bursts, while others return more passively to the resting potential [1-3].

A full mechanistic understanding that explains the function of the dLGN on the basis of neuronal morphology, physiology and circuitry is currently lacking. One way to address this question is to develop and investigate mathematical models of the involved cells and their interactions. While detailed models of the well studied TC cells exist, previous models of the less studied dLGN INs are simplified and use only passive dendritic properties. Several ion channels are present in the dendrites of dLGN INs [4-6], and may be of particular importance in these neurons, as their dendrites have not only postsynaptic contacts for excitatory retinal input, but also presynaptic terminals for inhibitory output to TC-cell dendrites [7].

We here present a detailed compartmental model of a dLGN IN with a detailed morphology and active dendritic, as well as somatic, conductances. The simulation tool NEURON (http://neuron.duke.edu/) was used for the model. The conductance values were constrained by somatic voltage recordings from two dLGN INs under 8 experimental conditions. The model reproduces qualitative features in the experimentally recorded response patterns, as well as quantitative data on the firing frequency

\footnotetext{
* Correspondence: geih@umb.no

${ }^{1}$ IMT, Norwegian University of Life Sciences, Ås, NO-1432, Norway

Full list of author information is available at the end of the article
}

as a function of injected current. We show that relative differences in conductance values, rather than differences in ion channel composition, explain the differences in the response properties of the two neurons, and can account for the various response patterns listed above. The model lays the foundation for studying the function of the dLGN IN and its interactions with TC cells within a network context, and does also in its own right give new insights in the properties of dLGN IN activity.

\section{Acknowledgements}

We acknowledge support from the eScience program (eNEURO) of the Research Council of Norway

\section{Author details}

${ }^{1}$ IMT, Norwegian University of Life Sciences, Ås, NO-1432, Norway. ${ }^{2}$ Department of Physiology, University of Oslo, Oslo, NO-0317, Norway. ${ }^{3}$ Institute of Biophysics, National Research Council, Palermo, IT-90146, Italy.

Published: 18 July 2011

\section{References}

1. Pape HC, McCormick DA: Electrophysiological and pharmacological properties of interneurons in the cat dorsal lateral geniculate nucleus. Neuroscience 1995, 68:1105-1125.

2. Williams SR, Turner JP, Anderson CM, Crunelli V: Electrophysiological and morphological properties of interneurones in the rat dorsal lateral geniculate nucleus in vitro. J. Physiol 1996, 490:129-147.

3. Zhu JJ, Uhlrich DJ, Lytton WW: Burst firing in identified rat geniculate interneurons. Neuroscience 1999, 91:1445-60.

4. Munsch T, Budde T, Pape HC: Voltage-activated intracellular calcium transients in thalamic relay cells and interneurons. Neuroreport 1997, 8:2411-2418.

5. Zhu JJ, Heggelund P: Muscarinic regulation of dendritic and axonal outputs of rat thalamic interneurons: a new cellular mechanism for uncoupling distal dendrites. J. Neurosci 2001, 21:1148-59.

6. Acuna-Goycolea C, Brenowitz SD, Regehr WG: Active dendritic conductances dynamically regulate GABA release from thalamic interneurons. Neuron 2008, 57:420-31.

7. Hamos JE, Horn SCV, Raczkowski D, Uhlrich DJ, Sherman SM: Synaptic connectivity of a local circuit neurone in lateral geniculate nucleus of the cat. Nature 1985, 317:618-621.

doi:10.1186/1471-2202-12-S1-P222

Cite this article as: Halnes et al:: A multi-compartment model for interneurons in the dorsal lateral geniculate nucleus. BMC Neuroscience 2011 12(Suppl 1):P222.

\section{() Biomed Central}

(c) 2011 Halnes et al; licensee BioMed Central Ltd. This is an open access article distributed under the terms of the Creative Commons Attribution License (http://creativecommons.org/licenses/by/2.0), which permits unrestricted use, distribution, and reproduction in any medium, provided the original work is properly cited. 